
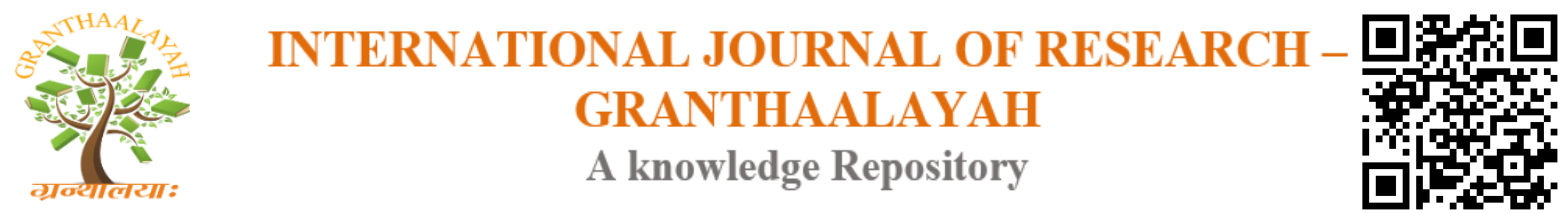

Social

\title{
STUDY OF SPIRITUAL INTELLIGENCEAMONG D.EL.ED. STUDENTS
}

\author{
Santosh Pal ${ }^{* 1}$ \\ ${ }^{* 1}$ Research Scholar, Department of Education, University of Allahabad, Prayagraj, Uttar \\ Pradesh, India
}

\begin{abstract}
The present study has been conducted to explore the status of development of spiritual intelligence among D.El.Ed. students. 92 students were selected as the sample for the study. Spiritual Intelligence Scale (SIS) developed by K. S. Misra was used to collect the data from students of D.El.Ed. I and III semester. t-ratio was computed to analyze the data. The significant gender, and locality differences in spiritual intelligence score are found. Male students are found more spiritually intelligent than females. Urban students had greater spiritual intelligence than rural students. No significant difference was found in the spiritual intelligence of D.El.Ed. I and III semester students.

Keywords: Spiritual Intelligence; D.El.Ed; Students; Grade Level; Gender; Male; Female; Rural; Urban.

Cite This Article: Santosh Pal. (2019). "STUDY OF SPIRITUAL INTELLIGENCEAMONG D.EL.ED. STUDENTS." International Journal of Research - Granthaalayah, 7(7), 143-147. https://doi.org/10.29121/granthaalayah.v7.i7.2019.740.
\end{abstract}

\section{Introduction}

Today, religion and spirituality are recognized as distinct concepts which can be clearly distinguished yet they overlap with one another on specific aspect of search for the higher transcendent reality which often takes shape of sacred in religious discourses (Miller \& Thoresen, 2003). Spirituality today is seen as people's phenomenon, having a humanistic focus on institutional and interpersonal values and behaviors that can be experienced within or outside the domain of religious faith (Elkins, 2001).

Bhawuk (2003) defines spirituality as envisaged as a deep rooted phenomenon in Indian context. It is a deep-rooted phenomenon and in earlier times, it used to be revered as important goals of one's life. For centuries, India has been a mystical land of meditation, contemplation and enlightenment where spiritual traditions flourished and still continuing to inspire millions.

According to Bhawuk (2011), "Spirituality has been appreciated since time immemorial in Indian culture, and it is no wonder that many spirituality inventions have come from India. Since 
individuals strive to excel in fields compatible with their cultural values, even in contemporary times, India has seen the development of many geniuses in the spiritual sector. According to Madan (2014), unlike in the West, spirituality is embedded in the way of life of masses in India and hence cannot be rigidly defined with specific terminology. With rich legacy of spiritual teachings by great seekers, India continues to be known as the land of spiritual wisdom offering an invaluable insight into the higher states of human consciousness and various paths to attainment of pure bliss.

It has also seen parallel momentum near theoretical and empirical exploration of multiple elements of spiritual growth, particularly in education, in line with the increasing body of spirituality studies (Miller, 2012). The prevalent element of many modern research in the region is spiritual growth as an aspect of meaning-making process. While some experts emphasize the role of spirituality in adult and higher schooling in particular (English \& Gillen, 2000). Others explore the link between spiritual growth and the moral or ethical foundations of education. Aspects of religious growth regarding human engagement to social justice and community work are also being researched (Tisdell 2002). As Dr. Radhakrishnan (1988) rightly remarked, education according to Indian culture is not a means of earning a living, but an initiation into the spiritual existence and preparation of human beings in persuading reality and the exercise of virtue. The argument for incorporating the spiritual dimension into teacher education is becoming stronger given the main theme of the National Curriculum Framework for Teacher Education (NCFTE, 2009), which reads on its cover page as, ' NCFTE 2009: Towards creating a competent and humane teacher.' Being Humane denotes a focus on humanistic values and issues inseparable from being spiritual. The paper reaffirms the position by proposing that "teacher education programs should help educators or prospective educators develop social sensitivity and awareness and finer human sensitivities". It further adds that learning has to be viewed as a search for meaning out of personal experiences. One can understand the importance of this research in the increasing's context acceptance of spirituality as an intrinsic element of human humans, including that of teacher teachers, and its growth is therefore highly essential to their general private, professional and social well-being. The present study has been conducted to explore the status of development of spiritual intelligence among D.El.Ed. students.

\section{Objectives}

Objectives of the study are as follows-

1) To find out whether students of D.El.Ed. I and D.El.Ed. III semester differ from one another in spiritual intelligence.

2) To find out whether male and female D.El.Ed. students differ from one another in their spiritual intelligence.

3) To find out whether D.El.Ed. students belonging to rural and urban areas differ from one another in spiritual intelligence.

\section{Hypotheses}

The following hypotheses were tested-

1) There is no significant difference in spiritual intelligence of D.El.Ed. I and D.El.Ed. III semester students. 
2) There is no significant difference in spiritual intelligence of male and female D.El.Ed. students.

3) There is no significant difference in spiritual intelligence of D.El.Ed. students belonging to urban and rural areas.

\section{Method}

Sample: The sample comprised of 92 participants (46 males, and 46 females) of D.El.Ed. I and D.El.Ed. III semesters. Students were selected from two private teacher training colleges of Lucknow, Uttar Pradesh, India. The investigator used descriptive method of research for the present study. Spiritual intelligence was measured with the help of 'Spiritual Intelligence Scale (SIS)'developed by K. S. Misra andt-ratios were computed to analyze the data.

\section{Results}

Table 1: Means and t ratio showing differences between D.El.Ed.I and D.El.Ed.III semester students in spiritual intelligence

\begin{tabular}{|l|l|l|l|l|l|l|}
\hline Grade Level & $\mathbf{N}$ & Mean & S.D. & df & t-ratio & \\
\cline { 1 - 6 } D.El.Ed.I & 46 & 165.72 & 18.66 & 90 & .243 & \\
\cline { 1 - 5 } D.El.Ed.III & 46 & 164.74 & 19.90 & & & \\
\hline
\end{tabular}

T-ratios were computed to compare D.El.Ed.I and D.El.Ed.III semester students on spiritual intelligence scale. Means, Standard Deviations for students of both the semesters on spiritual intelligence are shown in table 1. A look at the table shows that D.El.Ed. I semester students $(M=$ $165.72, S D=18.66)$ and D.El.Ed. III semester students $(M=164.74, S D=19.90)$ do not differ significantly on spiritual intelligence scale, $(t=0.243, p>.05)$. The null hypothesis that "there is no significant difference in spiritual intelligence of D.El.Ed. I semester and D.El.Ed. III semester students" is accepted.

Table 2: Means and t ratio showing differences between male and female D.El.Ed. students in spiritual intelligence

\begin{tabular}{|l|l|l|l|l|l|l|}
\hline Gender & N & Mean & S.D. & df & t-ratio & \\
\hline Male & 46 & 169.35 & 20.72 & 90 & $2.098^{*}$ & \\
\cline { 1 - 5 } Female & 46 & 161.11 & 16.75 & & & \\
\hline
\end{tabular}

*significant at .05 level

T-ratios were computed to compare male and female students studying D.El.Ed. on spiritual intelligence scale. Means, Standard Deviations for male and female students on spiritual intelligence are shown in table 2. Table shows that scores on the spiritual intelligence scale are higher for male $(M=169.35, S D=20.72)$ than for female $(M=161.11, S D=16.75)$ D.El.Ed. students, $(t=2.098, p<.05)$. Therefore, null hypothesis that "there is no significant difference in spiritual intelligence of male and female D.El.Ed. students" is rejected. 
Table 3: Means and t ratio showing differences between urban and rural D.El.Ed. students in spiritual intelligence

*significant at .05 level

\begin{tabular}{|l|l|l|l|l|l|l|}
\hline Locality & N & Mean & S.D. & df & t-ratio & \\
\cline { 1 - 4 } Urban & 30.00 & 172.67 & 15.58 & \multirow{2}{*}{90} & $2.672 *$ & \\
\cline { 1 - 5 } Rural & 62.00 & 161.63 & 19.84 & & & \\
\hline
\end{tabular}

t-ratios were computed to compare urban and rural D.El.Ed. students on spiritual intelligence scale. Means and Standard Deviations for urban and rural students on spiritual intelligence are shown in table 3. It is depicted in the table that urban D.El.Ed. students $(M=172.67, S D=15.58)$ have higher score on spiritual intelligence scale than rural D.El.Ed. students $(M=161.63, S D=19.84),(t=$ 2.672, $p<0.05)$. Therefore, null hypothesis that "there is no significant difference in spiritual intelligence of D.El.Ed. students belonging to urban and rural areas" is rejected.

\section{Discussion}

The results of the present study show that students of D.El.Ed. I and D.El.Ed. III semester have equal spiritual intelligence. The reason behind this may be that in India spirituality is commonly viewed as an integral part of religious experience and in teacher course no efforts are made to develop spiritual among students.

It has also been found that male students have shown higher spiritual intelligence than female students. This finding is contrary to Pant and Srivastava (2017) who found no significant difference between male and female students in terms of spiritual intelligence.

Environment plays vital role in development of spiritual behaviour and this study has revealed that D.El.Ed. students belonging to urban area have more spiritual intelligence in comparison to students belonging to rural area. The experiences of students growing up in an urban, more crime, more exposure to socioeconomic stressors may be responsible for increased spiritual intelligence.

\section{References}

[1] Bhawuk, D. P. S. (2003). 'Culture's Influence on Creativity: The Case of Indian Spirituality'. International Journal of Intercultural Relation, 27 (1), 1-22

[2] Bhawuk, D.P.S., (2011). Spirituality and Indian Psychology: Lessons from Bhagwad Gita. New Delhi. Springer.

[3] Elkins, D. N. (2001). Beyond religion: Toward a humanistic spirituality. In K. J. Schneider,J. T.Bugental, \& J. F. Pierson (Eds.), The handbook of humanistic psychology: Leading edges in theory, research and practice. Thousand Oaks, CA: Sage.

[4] English, L. M., \& Gillen, M. A. (Eds.) (2000). Addressing the Spiritual Dimensions of Adult Learning: What Adult Educators can do. San Francisco: Jossey-Bass

[5] Madan. G. (2013). Spirituality and its Psychological Impact on Youth. Unpublished Doctoral thesis, University of Delhi.

[6] Miller, L. J. (2012). The Oxford Handbook of Psychology and Spirituality. New York: Oxford University Press

[7] Miller, W., \& Thoresen, C. (2003). Spirituality, Religion, and Health: An Emerging Research Field. American Psychologist, 58(1), 24-35. 
[8] Pant, N., \& Srivastava, S. (2017). The Impact of Spiritual Intelligence, Gender and Educational Background on Mental Health among College Students. Journal of Religion and Health, 58(1), 87108

[9] Radhakrishnan (1988). The Hindu view of Life. London, England: Unwin.

[10] Tisdell, E. J. (2002). Spiritual Development and Cultural Context in the Lives of Women Adult Educators for Social Change. Journal of Adult Development, 9(2), 127-140.

*Corresponding author.

E-mail address: santosh.pal@yahoo.com 